\title{
Violência contra crianças e adolescentes e pandemia - Contexto e possibilidades para profissionais da educação
}

\author{
Violence against children and adolescents and the pandemic - Context and possibilities for education \\ professionals
}

Violencia contra niños, niñas y adolescentes y pandemia - Contexto y posibilidades para los profesionales de educación

\begin{abstract}
Ana Paula França de Oliveira ${ }^{1}$ (1) Marina Soares de Souza ${ }^{2}$ (1) Fabiano Henrique de Oliveira Sabino² (1) Aparecido Renan Vicente ${ }^{2}$ (1) Diene Monique Carlos ${ }^{1,2}$
\end{abstract}

1. Universidade Federal de São Carlos, Departamento de Enfermagem. São Carlos, SP, Brasil.

2. Universidade Federal de São Carlos, Programa de Pós-Graduação em Enfermagem. São Carlos, SP, Brasil.
Autor correspondente: Diene Monique Carlos. E-mail: diene_enf@hotmail.com

Recebido em 18/06/2021. Aprovado em 15/09/2021.

\section{Resumo}

Objetivo: compreender as percepções de profissionais da educação sobre as violências contra crianças e adolescentes em contexto de pandemia pela Covid-19. Método: pesquisa com abordagem qualitativa, ancorada no Paradigma Complexo, realizada com sete profissionais da educação entre setembro e outubro de 2020. A coleta de dados se deu por entrevistas semiestruturadas realizadas em plataforma virtual gratuita, sendo os dados analisados tematicamente. Resultados: emergiram dois temas finais "Violência e pandemia" e "(Não) percepção de possibilidades de atuação". A violência contra crianças e adolescentes é vislumbrada como fenômeno multidimensional pelos participantes. Pelas especificidades de maior ocorrência nas famílias, as alterações da vida impostas pela pandemia, em especial, o afastamento escolar, podem implicar no aumento de casos e maior dificuldade para identificação de violências contra essa população. Os impactos à saúde mental de crianças e adolescentes nesse período foi reforçado. Conclusão e implicações para a prática: apesar da compreensão de maior exposição às violências durante a pandemia, os profissionais não conseguiram propor estratégias para enfrentamento. Novos estudos sobre o tema com diferentes atores envolvidos, e articulação intersetorial para enfrentamento do fenômeno, são necessários.

Palavras-chave: Adolescente; COVID-19; Criança; Isolamento Social; Violência.

\section{Abstract}

Objective: to understand the education professionals' perception about violence against children and adolescents in the COVID-19 pandemic context. Method: a research study with a qualitative approach, anchored in the Complex Paradigm, carried out with seven education professionals between September and October 2020. Data collection took place through semi-structured interviews carried out on a free virtual platform, and the data were thematically analyzed. Results: Two final themes emerged: "Violence and the pandemic" and "(Non)perception of action possibilities". Violence against children and adolescents is seen as a multidimensional phenomenon by the participants. Due to the specificities that occur more frequently in families, the life changes imposed by the pandemic, especially distancing from the school, can lead to an increase in the number of cases and to greater difficulty identifying violence against this population. The impacts on children's and adolescents' mental health during this period were reinforced. Conclusion and implications for the practice: despite the understanding of greater exposure to violence during the pandemic, the professionals were unable to propose coping strategies. New studies on the subject matter with different actors involved are needed, as well as intersectoral articulation to face the phenomenon.

Keywords: Adolescent; COVID-19; Child; Social Isolation; Violence.

\section{Resumen}

Objetivo: comprender las percepciones de los profesionales de la educación sobre la violencia contra niños y adolescentes en el contexto de pandemia por Covid-19. Método: investigación con enfoque cualitativo, anclada en el Paradigma Complejo, realizada con siete profesionales de la educación entre septiembre y octubre de 2020. La recolección de datos se llevó a cabo a través de entrevistas semiestructuradas realizadas en una plataforma virtual libre, y los datos fueron analizados temáticamente. Resultados: Surgieron dos temas finales “Violencia y pandemia” “(No) percepción de posibilidades de actuación”. La violencia contra niños y adolescentes es vista por los participantes como un fenómeno multidimensional. Debido a las especificidades que ocurren con mayor frecuencia en las familias, los cambios en la vida que impone la pandemia, especialmente el alejamiento de las escuelas, pueden conllevar un aumento de casos y una mayor dificultad para identificar la violencia contra esta población. Se reforzaron los impactos en la salud mental de niños y adolescentes durante este período. Conclusión e implicaciones para la práctica: a pesar de comprender que se manifiesta una mayor exposición a la violencia durante la pandemia, los profesionales no pudieron proponer estrategias de afrontamiento. Se advierte la necesidad de contar con nuevos estudios sobre el tema, que incluyan a los diferentes actores involucrados, con articulación intersectorial para enfrentar el fenómeno.

Palabras clave: Adolescente; COVID-19; Niño; Aislamiento Social; Violencia 


\section{INTRODUÇÃO}

A violência é entendida como o uso intencional da força ou do poder físico, real ou em ameaça, contra uma pessoa, grupo ou comunidade, que resulte ou tenha grande possibilidade de resultar em injúria, morte, dano psicológico, privação ou alteração de desenvolvimento ${ }^{1}$. Pelas especificidades do fenômeno, atinge de forma mais grave alguns grupos considerados vulneráveis, como crianças e adolescentes. No Brasil, os acidentes e violências aparecem como primeira causa de mortalidade em crianças maiores de um ano e adolescentes. Ademais, violências ocorrem comumente em um espaço de relações de confiança, responsabilidade ou poder - o espaço doméstico ou intrafamiliar, usados neste estudo como sinônimos².

A Organização Mundial da Saúde (OMS) lançou, em 2014, um relatório com dados sistematizados de 133 países, correspondentes a 6,1 bilhões de pessoas, representando $88 \%$ da população mundial. Esse relatório indicou que, aproximadamente, um em cada quatro adultos referem ter sofrido violência física quando crianças; $36 \%$ referem ter sofrido violência psicológica quando crianças; e $20 \%$ das mulheres e $5-10 \%$ dos homens referem ter sofrido violência sexual quando crianças ${ }^{3}$. A violência contra crianças e adolescentes, pela especificidade da fase de crescimento e desenvolvimento em que ocorre, leva a alterações cerebrais que aumentam o risco de problemas mentais, físicos e de comportamento na fase adulta. Ainda é importante ressaltar que ser vítima de violência enquanto criança pode aumentar o risco dessa pessoa ser vítima ou perpetradora de outras formas de violência na adolescência e fase adulta ${ }^{3,4}$.

A emergência sanitária provocada pela Coronavírus Disease 2019 (COVID-19), caracterizada como pandemia pela OMS, no início de 2020, trouxe como uma das principais medidas de contenção da disseminação da doença o distanciamento social entre as pessoas ${ }^{5}$. NesteNesse sentido, escolas foram fechadas trazendo impacto psicossocial para a saúde de crianças e adolescentes. A escola ocupa um lugar na vida de crianças e adolescentes para além do educacional, em especial, para aqueles em vulnerabilidade social. Essa população tem suas necessidades nutricionais e protetivas nesse espaço, ainda considerando que a principal instituição identificadora de situações de violências é a escola ${ }^{6,7}$.

Assim, este estudo buscou responder às questões: como os profissionais da educação percebem as situações de violências contra crianças e adolescentes durante a pandemia? Que elementos estão presentes nesse fenômeno? A literatura brasileira se apresenta incipiente no olhar para essas questões pela saúde, em especial, na perspectiva de profissionais, diretamente, envolvidos no cuidado de crianças e adolescentes ${ }^{8,9}$.

Para aproximação desse objeto, apoiou-se no Paradigma Complexo, que visa compreender o significado de fenômenos caracterizados por sua instabilidade, não linearidade e pela impossibilidade de serem descritos em um número de passos e espaço de tempo finitos. Os distintos elementos desse fenômeno permanecem em constante interação, da qual podem surgir propriedades desconhecidas. Tais elementos convivem com a incerteza e a mudança, na medida em que as partes interconectadas ou entrelaçadas mantêm vínculos capazes de gerar informações adicionais, no mesmo processo de ação, portanto, sempre há possibilidade de emergência do novo, do imprevisto. Podem ocorrer, ao mesmo tempo, elementos contraditórios que não se diluem, convivendo de forma articulada no fenômeno e constituindo um de seus princípios - o dialógico ${ }^{10}$.

Dessa forma, este estudo trouxe o objetivo de compreender as percepções de profissionais da educação sobre as violências contra crianças e adolescentes em contexto de pandemia pela Covid-19.

\section{MÉTODO}

Pesquisa de abordagem qualitativa, entendida como aquela destinada ao estudo das relações sociais; permite o reconhecimento das perspectivas dos participantes, diretamente, envolvidos em determinado fenômeno, e o respeito às suas singularidades e diversidades ${ }^{11}$. Foi ancorada no Paradigma Complexo, direcionada pelas noções de compreensão e contextualização. A primeira permite apreender os significados dos fenômenos, nas suas articulações com outros acontecimentos e objetos, numa construção dinâmica de feixes de relações. A segunda reflete uma perspectiva multidimensional no olhar ao fenômeno, para descoberta de como as coisas se tecem conjuntamente ${ }^{10}$.

O estudo foi realizado em município de médio porte, polo tecnológico do centro do estado de São Paulo. Possui 221.950 habitantes de acordo com censo de 2010, com estimativa para 2018 de 249.415 habitantes. O campo específico foi um distrito com, aproximadamente, 80.000 habitantes. Foi selecionada uma escola desse distrito, caracterizado como grupo exposto a alta vulnerabilidade social para um setor urbano, sendo classificada como categoria 5 (cinco) de acordo com o Índice Paulista de Vulnerabilidade Social (IPVS) de $2010^{12}$. A escola em questão foi inaugurada, em 2016, possuindo uma área construída de $4.008 \mathrm{~m}^{2}$ e com 12 salas de aula, além de salas de laboratórios e informática, centro de leitura, entre outros espaços. A escola atende alunos dos primeiros anos do Ensino Fundamental até os últimos anos do Ensino Médio, sendo um total de 18 turmas em ambos os turnos e com 578 matrículas regulares.

Os participantes do estudo foram profissionais de educação que possuem contato com os estudantes do Ensino Fundamental e Médio e possuíam acesso à Internet, mantendo o critério de anuência por meio do Termo de Consentimento Livre e Esclarecido - TCLE.

Esses professores foram convidados via on-line (Aplicativo WhatsApp), conforme sugestão e disponibilização dos contatos pela direção escolar, sendo a coleta realizada também via essa plataforma virtual. Na totalidade, foram convidados 15 profissionais para participação da pesquisa; destes, sete profissionais aceitaram participar. O TCLE foi inserido na plataforma on-line gratuita Formulários Google, para leitura do potencial participante após contato inicial da pesquisadora pelo WhatsApp e demonstração de interesse pelo profissional. Nesse contato inicial, foram explicados por mensagem de texto os riscos e benefícios, em especial, do 
ambiente virtual, e as estratégias e cuidado das pesquisadoras para minimizarem esses riscos. Foi relatado como seria o processo de coleta de dados, sendo detalhadas as informações a serem recolhidas pelos instrumentos no TCLE. Ao final do TCLE, os participantes poderiam concordar ou discordar em participar da pesquisa ao clicar no link correspondente para sua anuência ou não. Uma cópia do TCLE foi encaminhada aos participantes pelo correio eletrônico informado, reforçando a importância da guarda dessa cópia.

Foram utilizados como instrumentos para coleta de dados entrevistas semiestruturadas. Para caracterização dos participantes, foi utilizado um questionário via Formulários Google. A entrevista semiestruturada partiu de certos questionamentos básicos, guiados por um roteiro que norteiam uma conversa com finalidade definida, não apresentando nenhum obstáculo e não tendo meios para prever todas as condições ou situações do trabalho de campo ${ }^{13}$. Foram utilizadas as seguintes questões disparadoras: o que você entende por violências contra crianças e adolescentes? Como você acha que estão esses casos nesse período de afastamento da escola? O que você acha que pode ser feito de intervenção agora e após a pandemia quanto a esse assunto?

As entrevistas foram realizadas nos meses de setembro e outubro de 2020 , com duração média de 25 minutos. Foram gravadas em aplicativo de gravação de áudio para celular e transcritas na íntegra. Os arquivos foram salvos em mídia digital, sob guarda e responsabilidade da pesquisadora responsável por cinco anos, não sendo mantidos em nuvens de arquivos; foi excluída qualquer identificação como nomes. Os profissionais foram identificados na ordem das datas das entrevistas com a inicial "P" para representar profissionais "P1, P2, P3...", a fim de garantir o anonimato das participantes.

Optou-se neste estudo por buscar a saturação de códigos; esta foi definida quando não aparecem elementos adicionais para resposta à questão de estudo e esses elementos foram compreendidos ${ }^{14}$. Essa saturação ocorreu na sexta entrevista, foi realizada mais uma entrevista para complementaridade dos dados.

A caracterização dos participantes foi apresentada por meio de estatística descritiva. Os dados foram analisados mediante a análise temática reflexiva, proposta por Clarke e Braun ${ }^{15}$.Trata-se de uma análise com lógica indutiva, a partir dos dados, considerada um processo reflexivo, criativo, subjetivo e deliberativo. Traz uma sistemática e rigorosa aproximação para codificação e criação de temas, ao mesmo tempo fluida e recursiva. Seguimos as seguintes etapas: (I) familiarização com os dados: após transcrição das entrevistas; (II) codificação; (III) busca por temas; (IV) revisão de temas; (V) definição e nomeação dos temas; (VI) escrita final. Os conceitos de compreensão e contextualização nortearam o processo de coleta e análise de dados ${ }^{10}$.

O projeto de pesquisa foi aprovado pelo CEP-UFSCar sob o número CAAE 09272919.4.0000.5504, parecer ํㅜㄴ.215.561 de 22 de março de 2019, respeitando os critérios da Resolução do Conselho Nacional de Saúde nำ466/2012 e nํ510/2016.

\section{RESULTADOS}

Os participantes do estudo foram sete professores das áreas de matemática, geografia, letras, química, história e educação física. A maioria possuía entre 31 e 40 anos ( $n=3,42,8 \%$ ). Quatro dos professores apresentavam até 6 anos de formação $(57,15 \%)$, o restante possuía mais de 12 anos de formação. O tempo de atuação da maior parte dos professores na escola é de até um ano $(n=4,57,15 \%)$, tendo os outros até quatro anos de atuação. Seis participantes afirmaram que o tema violência foi abordado durante sua própria formação, e três participaram de curso ou palestra sobre o tema durante atuação profissional ( $n=42,86 \%$ ).

A partir das falas, emergiram dois temas finais intitulados "Violência e pandemia" e "(Não) percepção de possibilidades de atuação".

\section{Violência e pandemia}

A violência foi relatada pelos professores com uma perspectiva ampla, que pode ocorrer em diferentes manifestações, inclusive relacionada a ausências do Estado:

[...] não sei se você tá falando, especificamente, sobre violência física ou psicológica, mas em ambos os casos na minha opinião é crime, independente do grau sabe, acredito que tenha outras maneiras de se tratar, se lidar com uma criança ou com um adolescente que não envolvam qualquer tipo de violência, então, pra mim a pessoa que comete uma violência contra uma criança ou um adolescente tá cometendo um crime na verdade [...] (P6).

[...] a violência contra crianças e adolescentes é algo inaceitável, é obvio que nós sabemos que há várias vertentes da violência, desde a física a verbal e também a ausência de assistência por parte do Estado no meu ponto de vista se caracteriza como uma violência... por exemplo, quando o estado age de má fé, e não cumpre com os compromissos estabelecidos por lei, ... a falta de material escolar, a falta de segurança é no a redor da escola, a falta de estrutura [...] (P7).

Os professores destacaram que as violências intrafamiliares contra crianças e adolescentes sempre ocorreram, mas devido a pandemia outros elementos se sobrepuseram àqueles já existentes - como o isolamento social, maior tempo de contato, dificuldades familiares e conflitos parentais:

[...] se são famílias estruturadas, que têm uma relação de afeto, carinho e respeito, possivelmente, a situação de violência não aumentou, mas como sabemos que na realidade não funciona dessa forma pode ser que os casos de violência durante a pandemia podem ter aumentado, não só em relação as crianças, mas também em relação a casais, briga de marido e mulher que pode ter acarretado em violência doméstica, inclusive ter causado alguma 
morte ou algum dano mais, como é que eu posso dizer. Mais severo, digamos assim [...] (P1).

[...] tenho certeza que isso até duplicou, boa parte deles se encontra em situação de vulnerabilidade e já viviam... neste ambiente de conflitos, somado a essa situação da pandemia a falta de trabalho, vícios, enfim, com certeza isso duplicou (P4).

Você ficando esse tempo todo, esses seis meses dentro de casa eu acho que a criança ficou entediada, e aí, logicamente, né? Os pais desempregado passando necessidade com o filho dentro de casa o tempo inteiro pedindo as coisas o pai e a mãe não poder dar, se a criança estivesse na escola, estivesse em outro lugar, se não tivesse a pandemia, isso seria tanto, porque essas necessidades que a criança passa dentro de casa ela supre com as amizades que ela tem dentro da escola, né? Com os colegas e etc [...] (P2).

Algumas falas acabam por reforçar a culpabilização de crianças e adolescentes às violências sofridas, como a última citada. Uma questão reiterada foi a ocorrência de violências no domicílio, portanto com maior exposição neste momento, e nisso o afastamento escolar acabou por intensificar:

[...] principalmente, porque a gente tem muitos alunos com pais que são alcoólatras, é usuários de drogas né? Então, eu acho que era assim uma panela de pressão prestes a explodir o tempo inteiro né? Porque todo mundo, muita gente dentro de casa, às vezes, pequenas, com gente, às vezes, que bebe, que usa droga, todo mundo o tempo inteiro junto, então, eu acho que tenha aumentado. A gente viu casos de alunos em situação de fome, então, acho que isso também deve ter influenciado bastante sabe $[\ldots](\mathrm{P} 6)$.

[...] eu acho que, com certeza, as crianças que estão nessas situações aí de vulnerabilidade eles ficaram muito mais expostos a este tipo de violência por parte de quem cuida deles né? [...]. Tem crianças que ficaram mais abandonadas do que já são e esses casos devem ter assim, não aumentado, mas nas crianças que já sofriam agressões eles devem ter sido agredidos ainda mais né, porque está dentro de casa, só com o pai, sem ninguém ver, vai saber [...] (P3).

Nesse sentido, os professores destacaram a instituição escolar como único espaço de identificação e intervenção frente a situações de violências envolvendo crianças, adolescentes e suas famílias pelo convívio cotidiano:

[...] ela te dá alardes de várias maneiras dentro da escola, onde é o espaço se não é a segunda é a primeira casa do aluno é a escola né? [...]. Pode acontecer porque, às vezes, o único meio de um contato responsável, de alguém que possa encaminhar a situação pra uma instituição responsável por essas situações é a escola, né? [...] (P2).

[...] se a criança e o adolescente relatar algum caso de violência que a escola possa intervir, entrar em contato com o conselho tutelar e passar a situação que está acontecendo é mais viável desenvolver algum tipo de intervenção. Mas, nesse momento específico que nós não estamos tendo muito contato com as crianças, com os adolescentes fica bem complicado intervir de alguma forma [...] (P1).

[...] porque, infelizmente, na escola nós somos, assim, o único contato do Estado com esse tipo de criança né? Se a gente vê que a criança está com alguma marca, ou que aconteceu alguma coisa estranha, ou que o aluno fala com alguém é através da escola que a gente pode acionar né? O conselho tutelar, é a polícia militar e ficar um pouco de olho no aluno né [...] (P3).

\section{(Não) percepção de possibilidades de atuação}

Apesar de destacarem a escola como único espaço para identificação oportuna de situações de violências contra crianças e adolescentes, os professores não perceberam possibilidades de atuação durante a pandemia. Mesmo antes dessa situação de emergência sanitária, ocorriam ações pontuais e com comprometimento de algumas pessoas:

[...] agora que a gente não está tendo muito contato com crianças e com os adolescentes eu acho um pouco difícil desenvolver algum tipo de intervenção para evitar os casos de violência, que podem não só ser física como também psicológica e moral né? [...] (P1).

[...] existe um grupo específico dentro da escola da qual fica responsável por este setor, e comunica então as autoridades, então eu acredito que ficou mais fácil, na verdade menos difícil, porque fácil nunca é, lidar com a violência nunca é fácil, mas tem a questão de você se envolver de repente no papel do professor lembrando que ele tem ali 50 minutos pra mais com 35 a40 alunos dentro de uma sala de aula, e por mais que ele tenha um respaldo pelo trabalho ele está ali sozinho, então, da minha parte, pelo menos, sempre existiu muita insegurança com relação a isso... até pra que eu não me comprometa [...] (P2).

Os entrevistados pontuaram a importância da rede de proteção social contra crianças e adolescentes estar mais articulada, com olhar especial pelo Conselho Tutelar:

[...] acho que o conselho tutelar, agora mais do que nunca, tem que tá mais próximo dessas famílias, acho que muito mais do que a gente, assim, nesse momento... após a pandemia é fazer a retomada do que a gente já 
fazia antes, que é observar esses alunos, sempre tentar descobrir se tá acontecendo alguma coisa diferente em casa, é sabe, e trabalhar esses temas na escola, apesar de ser algo que tá bem difícil de ser feito nos últimos tempos, né? [...] (P6).

Um dos principais elementos presentes nessa dificuldade para enfrentamento de situações de violências é o afastamento físico e afetivo da escola. Os professores relataram que a dificuldade de muitos estudantes acessarem a Internet reforça esse distanciamento:

[...] então, acredito que, e também tem a situação enquanto agora em aula remota, tem aluno que não responde, tem aluno que não tem o aparelho, eu tenho uma aluna aonde a mãe tirou o aparelho dela [...] (P2).

[...] lá que é uma escola de periferia, é foi muito difícil a gente conseguir manter um contato com as crianças, e eu não sei se a escola conseguiu atingir $100 \%$ das crianças, de saber o que está acontecendo, como é que está a vida delas, é foi tudo muito complicado [...] (P3).

[...] na escola particular funciona porque todo mundo tem computador de última geração, tem internet, e pra nós do estado funciona? Eu tenho sabe quantos alunos? Tenho quase mil, sabe quantos que assiste o teletrabalho comigo? Se eu falar pra você que é coisa de 20 alunos é muito! [...] (P4).

Os professores ainda enunciaram a dificuldade em pensar ações à distância para tratar temas sensíveis, como as violências:

[...] mas, assim, as políticas de intervenção, elas precisam ser construídas é a longo prazo, e precisam de diálogo, precisam de encontros, e acho que on-line é difícil fazer; eu não tô falando que nós precisamos contratar ninguém pra isso, eu acho que o professor mediador e até nós mesmos professores podemos caminhar nesse sentido e construir algo pro ano que vem e pros próximos anos, porque essa pandemia ela vai deixar sequelas, emocionais, seja nos adolescentes, seja nos adultos [...] (P7).

Nesse aspecto, pontuaram os impactos à saúde mental de crianças e adolescentes pela pandemia, ainda vulnerabilizados por violências e outras ausências, que se exacerbaram. Reforçaram a importância do acolhimento e cuidados pós-pandemia:

[...] eles perderam essa parte do dia deles, perderam essa parte da vida eu diria, porque são mais de sete meses que é esse contexto foi retirado da vida deles e não houve um preparo pra isso; precisam do ambiente escolar pra socializar [...] (P7).
[...] por entender como que esse aluno vai retomar dessa pandemia, boa parte deles a gente não tem conhecimento nem de onde estão [...] (P2).

[...] então, eu acho que ter um acolhimento assim, eles terem contato com psicólogos com todo mundo porque, às vezes, os alunos nem se sentem muito confortáveis de se abrir com professores, né? Nesse caso, teria que ser uma ajuda profissional, assim, pra colher eles depois deles terem ficado tanto tempo assim de quarentena [...] (P3).

\section{DISCUSSÃO}

A violência contra crianças e adolescentes se apresenta de forma multidimensional, produzida e reproduzida por vários elementos que se articulam para emergência desse fenômeno. Para além da complexidade intrínseca ao fenômeno, sobrepõese os elementos presentes na pandemia. Essencialmente, a necessidade de afastamento físico e isolamento domiciliar/ familiar como principal elemento para enfrentar a disseminação do vírus precisa ser considerado em perspectiva dialógica. Para crianças e adolescentes em situação de violência essa medida pode potencializar a ocorrência desses eventos, além de manterem aqueles que não estão mais propensos a tais violências ${ }^{10}$. Os profissionais da educação reforçaram esse olhar polidimensional ao fenômeno, apesar das dificuldades na construção de estratégias para alcançá-lo.

O contexto em que emerge esse novo fenômeno, da violência contra crianças e adolescentes, é entretecido pelas alterações da vida cotidiana pela pandemia ${ }^{10}$. A literatura traz que as violências contra grupos vulneráveis, em especial, crianças, adolescentes e mulheres, são maiores aos fins de semana, feriados, férias e desastres naturais ${ }^{16}$. Esse fato é relacionado ao maior convívio dessa população com seus familiares, geralmente, os autores de violências, bem como afastamento de sua possível rede de apoio; crianças e adolescentes pelo vulnerável processo de desenvolvimento, podem estar ainda mais expostos. Nesse âmbito, ressalta-se que crianças e adolescentes que precisam conviver com famílias que estão lidando com fatores estressores adicionais, como na pandemia - problemas financeiros, desemprego, aumento de uso de substâncias, maior carga de trabalho doméstico - estão mais vulneráveis a violências ${ }^{17,18}$ Os participantes de nosso estudo reiteraram tais achados.

Ademais, epidemias prévias como aquelas causadas pelo vírus Ebola no Oeste da África, cólera e Zika vírus levaram a maiores taxas de violências domésticas. Para além do fenômeno do distanciamento social, cabe ressaltar a redução de financiamentos para serviços de saúde pública especializados e redução do acesso a serviços de saúde por essas populações pelas mudanças nas prioridades de atendimentos ${ }^{19}$. A mídia digital vem reforçando tais aspectos, incluindo maiores dificuldades de identificação dos casos de violências intrafamiliares que já se constituía como desafio aos serviços de proteção social antes da pandemia ${ }^{16,19}$. 
Os participaram reiteraram um olhar polissêmico às violências, inclusive trazendo as ausências do Estado como elemento condicionante e determinante destes fenômenos. Estudo realizado junto a famílias envolvidas em violências contra crianças e adolescentes corroborou tais achados, imprimindo ainda uma historicidade à reprodução de atos violentos. Políticas públicas e práticas reducionistas, fragmentadas e compensatórias necessitam ser substituídas, gradativamente, por olhares ampliados e pautados na integralidade ${ }^{20}$. Revisão de literatura sobre estratégias de enfrentamento à violência contra crianças, adolescentes e mulheres no contexto do isolamento social devido à covid-19 trouxe que os serviços de proteção social devem ser classificados como essenciais, inclusive com a garantia de atendimentos presenciais seguros na impossibilidade de atendimentos virtuais ${ }^{8}$.

Nesse sentido, no Brasil foi promulgada a Lei no 14.022 em 07 de julho de 2020, que dispõe sobre medidas de enfrentamento à violência doméstica e familiar contra populações vulneráveis, entre elas crianças e adolescentes, durante a pandemia da Covid-1921. Essa legislação reitera e garante a continuidade de processos e medidas protetivas a essas populações; o registro da ocorrência dessas situações por meio eletrônico ou telefônico; a manutenção de atendimentos virtuais, que não excluem a obrigação do poder público em manter o atendimento presencial ${ }^{21}$. Assim, busca-se superar a maior vulnerabilidade de crianças e adolescentes a violências imposta pelo isolamento social, em especial, pelo afastamento de escolas e unidades de saúde.

Apesar das demonstrações de maior ocorrência de violência contra crianças e adolescentes na pandemia, as subnotificações também se fazem mais presentes. Estudo brasileiro desenvolvido no Rio Grande do Sul analisou as taxas de notificações de violências contra crianças e adolescentes de 2015 a 2020, e alterações nas tendências devido à crise sanitária causada pelo Covid-19. Este estudo mostrou uma queda das notificações em 54\% em 2020 na comparação ao mesmo período de 2019. Os autores recomendaram o planejamento de ações intersetoriais estratégicas para permitir a identificação de casos suspeitos e intervenção oportuna para garantia dos direitos de crianças e adolescentes em tempos adversos ${ }^{9}$.

Outro estudo desenvolvido na Flórida, Estados Unidos, examinou e estimou dados de forma transversal da distribuição de denúncias de maus-tratos infantis em março e abril de 2020, os dois primeiros meses em que as escolas estiveram fechadas no estado. Os autores pontuaram que a despeito da expectativa de que o estresse financeiro, mental e físico relacionado à Covid-19 poderia resultar em mais casos de maus-tratos, o número de notificações foi $27 \%$ menor ao esperado para esses dois meses ${ }^{7}$. Nesse sentido, tais dados corroboram as falas dos professores, em que os mesmos desvelaram a escola como principal e, em alguns territórios, o único espaço para identificação de situações de violências

Como importante contexto de desenvolvimento humano, a escola ocupa lugar privilegiado para construção e exercício da autonomia e identidade por crianças e adolescentes para além das famílias ${ }^{6}$. Crianças e adolescentes vulneráveis a violências foram separados de um recurso valioso para proteção e enfrentamento desse fenômeno; estudo reforçou que quando escolas estão fechadas, casos de maus-tratos infantis são mais prováveis de permanecerem não identificados e/ou não notificados ${ }^{7}$. A rede de cuidado a crianças, adolescentes e suas famílias em situação de violências já era fragilizada antes da pandemia. Estudo desenvolvido junto a profissionais da atenção primária à saúde em município brasileiro de grande porte demonstrou que a rede construída possui vínculos intersetoriais reduzidos, com baixa densidade (pouco suporte) e homogêneos, levando a um cuidado fragmentado, pautado no modelo biomédico ${ }^{22}$.

Conforme apontado por algumas falas, as escolas aderiram ao ensino remoto, entretanto aí convive outra dialógica ${ }^{10}$ - a maior parte das famílias brasileiras não possuem recursos tecnológicos ou rede de Internet para tal. Estudo australiano apontou que mesmo sabendo que a violência contra crianças e adolescentes ocorre em todos os grupos da sociedade durante a pandemia, crianças de grupos socioeconômicos desfavorecidos são mais representativas nas estatísticas ${ }^{23}$. Nesse momento, acessar essa população é mais difícil pelos equipamentos eletrônicos insuficientes, conexão à rede limitada ou a existência de crianças menores requerendo atenção e adultos insuficientes para apoiar ${ }^{23}$. Ademais, os espaços pouco privativos e seguros dos domicílios brasileiros precisam ser considerados ${ }^{8}$.

Considerando esse distanciamento da escola, estudos vem trazendo estratégias e possibilidades para identificação e enfrentamento das violências contra crianças e adolescentes s, $, 8,24^{\text {. }}$ Uma delas, corroborando dados deste estudo, é a proteção social básica ser considerada um serviço prioritário, com funcionamento estendido e maiores possibilidades de acessar famílias que estão em situação de vulnerabilidade ${ }^{23}$. Infelizmente, no Brasil, essa ação ainda é um desafio. Estudo recomendou que distritos escolares poderiam coordenar checagens virtuais entre profissionais treinados para reconhecer sinais de violências em crianças ou adolescentes vulneráveis ${ }^{7}$; no caso de limitação de Internet, poderia haver articulação intersetorial para visitas, atentando a condições sanitárias.

Nesse âmbito, os participantes citaram o Conselho Tutelar, que é um órgão constitucional responsável pela garantia dos direitos da criança e do adolescente no Brasil. Estudo trouxe a importância da manutenção do trabalho dos Conselhos Tutelares por plantão presencial, telefônico ou digital durante a pandemia ${ }^{16}$. Ações preventivas estratégicas, como a divulgação em massa de meios para comunicação de violências pela comunidade, além do fácil e gratuito acesso, são recomendadas?

O impacto à saúde mental de crianças e adolescentes pela pandemia e possíveis violências a que estão expostos tem sido referido em diversos estudos. Um estudo teórico refletiu sobre as implicações da pandemia na saúde mental de adolescentes ${ }^{25}$. Trouxe que essa população vivencia ambientes pouco sustentadores para o desenvolvimento saudável, sendo urgente a construção e implementação de ações interprofissionais promotoras de saúde mental aessa população; e ainda que são necessários 
estudos que vislumbrem a realidade brasileira ${ }^{25}$. Outro estudo com revisão narrativa de literatura trouxe que uma das principais consequências da pandemia será a implicação à saúde mental de crianças, adolescentes e suas famílias pelos diversos fatores - recessão econômica, lutos, conflitos. Os autores recomendaram o foco em populações com maior vulnerabilidade social, inclusive sem acesso à Internet, além de crianças e adolescentes com doenças crônicas, que já vivenciavam experiências adversas ou sofrimento mental e imigrantes/refugiados ${ }^{25}$.

\section{CONSIDERAÇÕES FINAIS E IMPLICAÇÕES PARA A PRÁTICA}

Os resultados permitiram compreender que a violência contra crianças e adolescentes é vislumbrada como fenômeno multidimensional pelos participantes. Pelas especificidades de maior ocorrência nas famílias, as alterações da vida impostas pela pandemia, em especial, o distanciamento social, pode implicar no aumento de casos e maior dificuldade para identificação de violências contra essa população. O afastamento da escola, inclusive pela dificuldade de acesso remoto a crianças e adolescentes pelos professores, foi entendido como principal elemento para maior vulnerabilidade às violências. Os impactos à saúde mental de crianças e adolescentes a partir de possíveis vivências conflituosas e/ou violentas foram reforçados; o cuidado interprofissional e intersetorial necessitam vislumbrar esse desafio e propor ações a curto e médio prazo.

Este estudo trouxe limitações. A primeira se refere à coleta de dados que trabalhou apenas com os áudios, dificultando o olhar para a comunicação não verbal. Outra limitação foi o uso da saturação por códigos, sendo que tais dados poderiam ser aprofundados com outras técnicas para alcance da saturação de significados. Essas limitações podem ser vislumbradas por novos estudos na área que são necessários, em especial, no contexto brasileiro, voltados a atores como famílias, gestores e profissionais de outros setores de proteção social.

Apesar das limitações, o presente estudo traz importantes implicações para a prática em Enfermagem e Saúde, a saber (1) construção de apoio e ações estratégicas intersetoriais com foco na escola, visto ser um equipamento que tem mantido contato com crianças e adolescentes, inclusive para apoio a visitas, respeitando condições sanitárias para aqueles em que não for possível contato remoto; (2) educação permanente dos profissionais de saúde, educação e assistência social sobre sinais suspeitos de violências contra crianças e adolescentes em tempos de pandemia; (3) construção de protocolos de ação intersetorial frente a esses casos; (4) construção de pergunta-padrão sobre segurança no domicílio para crianças e adolescentes; (5) divulgação em massa de canais de denúncias de violências contra crianças e adolescentes à comunidade; (6) desenvolvimento de ações promotoras de saúde mental a crianças, adolescentes, famílias e comunidades em tempos de pandemia.

\section{FINANCIAMENTO}

Conselho Nacional de Desenvolvimento Científico e Tecnológico. Auxílio à Pesquisa - Edital Universal no 28/2018. Projeto de pesquisa: Prevenção de violência nas relações de intimidade entre adolescentes: análise de uma intervenção. Coordenação: Diene Monique Carlos, Processo no 434214/2018-3. Fundação de Amparo à Pesquisa do Estado de São Paulo. Bolsa de Iniciação Científica concedida à Ana Paula França de Oliveira, Processo 2018/23296-6. Coordenação de Aperfeiçoamento de Pessoal de Nível Superior - Brasil (CAPES). Bolsa de Mestrado concedida à Marina Soares de Souza, Código de Financiamento 001.

\section{CONTRIBUIÇÕES DOS AUTORES}

Concepção do desenho do estudo. Ana Paula França de Oliveira. Diene Monique Carlos.

Coleta de dados. Ana Paula França de Oliveira. Diene Monique Carlos.

Análise dos dados. Ana Paula França de Oliveira. Diene Monique Carlos. Marina Soares de Souza. Fabiano Henrique de Oliveira Sabino. Aparecido Renan Vicente.

Interpretação dos dados. Ana Paula França de Oliveira. Diene Monique Carlos. Marina Soares de Souza. Fabiano Henrique de Oliveira Sabino. Aparecido Renan Vicente.

Redação do artigo ou revisão crítica relevante do conteúdo intelectual. Ana Paula França de Oliveira. Diene Monique Carlos. Marina Soares de Souza. Fabiano Henrique de Oliveira Sabino. Aparecido Renan Vicente.

Revisão e aprovação final da versão a ser publicada. Ana Paula França de Oliveira. Diene Monique Carlos. Marina Soares de Souza. Fabiano Henrique de Oliveira Sabino. Aparecido Renan Vicente.

Concordância com todos os aspectos do manuscrito em termos de veracidade ou integridade das informações. Ana Paula França de Oliveira. Diene Monique Carlos. Marina Soares de Souza. Fabiano Henrique de Oliveira Sabino. Aparecido Renan Vicente.

\section{EDITOR ASSOCIADO}

Antonio José de Almeida Filho (1)

\section{EDITOR CIENTÍFICO}

Ivone Evangelista Cabral (1)

\section{REFERÊNCIAS}

1. World Health Organization, Violence Prevention Alliance. Definition and typology of violence [Internet]. Geneva:WHO; 2014 [citado 2020 maio 28]. Disponível em: http://www.who.int/violenceprevention/approach/ definition/en/index.html

2. Ministério da Saúde (BR). Vigilância de violência doméstica, sexua e/ou outras violências: Viva/Sinan Brasil, 2011 [Internet]. Brasília: Ministério da Saúde; 2013. (Boletim Epidemiológico) [citado 2020 jul 20]. Disponível em: https://antigo.saude.gov.br/images/pdf/2014/ junho/11/BE-2013-44--9----VIVA-SINAN.pdf 
3. World Health Organization. Global status report on violence prevention 2014 [Internet]. Geneva:WHO; 2014 [citado 2020 maio 28]. Disponível em: https://www.who.int/violence_injury_prevention/violence/status_ report/2014/en/

4. Katz LF, Stettler N, Gurtovenko K. Traumatic stress symptoms in children exposed to intimate partner violence: the role of parent emotion socialization and children"s emotion regulation abilities. Soc Dev. 2016;25(1):47-65. http://dx.doi.org/10.1111/sode.12151.

5. World Health Organization. Coronavirus disease (COVID-19) outbreak: rights, roles and responsibilities of health workers, including key considerations for occupational safety and health [Internet]. Genebra: WHO;2020 [citado 2020 maio 28]. Disponível em: https://www.who.int/ publications-detail/coronavirus-disease-(covid-19)-outbreak-rights-rolesand-responsibilities-of-health-workers-including-key-considerationsfor-occupational-safety-and-health

6. Colao A, Piscitelli P, Pulimeno M, Colazzo S, Miani A, Giannini S. Rethinking the role of the school after COVID-19. Lancet Public Health. 2020;5(7):e370. http://dx.doi.org/10.1016/S2468-2667(20)30124-9. PMid:32464100.

7. Baron EJ, Goldstein EG, Wallace CT. Suffering in silence: how COVID-19 school closures inhibit the reporting of child maltreatment. J Public Econ 2020;190:104258. http://dx.doi.org/10.1016/j.jpubeco.2020.104258. PMid:32863462.

8. Lettiere-Viana A, Baraldi NG, Carlos DM, Fumincelli L, Costa LCR, Castro PC. Coping strategies for violence against children, adolescents and women in the context of social isolation due to covid-19: scoping review. Texto Contexto Enferm. 2021;30:e20200443. http://dx.doi. org/10.1590/1980-265x-tce-2020-0443.

9. Levandowski ML, Stahnke DN, Munhoz TN, Hohendorff JC, SalvadorSilva R. Impact of social distancing on reports of violence against children and adolescents in Rio Grande do Sul, Brazil. Cad Saude Publica. 2021;37(1):e00140020. http://dx.doi.org/10.1590/0102-311x00140020. PMid:33440409.

10. Morin E. Introdução ao pensamento complexo. 5. ed. Porto Alegre: Sulina; 2015.

11. Flick U. Introdução à pesquisa qualitativa. 3. ed. Porto Alegre: Artmed; 2009.

12. Assembleia Legislativa do Estado de São Paulo. Índice paulista de vulnerabilidade social [Internet]. 2010 [citado 26 jul 2020]. Disponível em: http://ipvs.seade.gov.br/view/index.php

13. Minayo MCS. O desafio do conhecimento: pesquisa qualitativa em saúde. 12. ed. São Paulo: Hucitec; 2014.

14. Hennink MM, Kaiser BK, Marconi VC. Code Saturation versus meaning saturation: how many interviews are enough? Qual Health Res. 2017;27(4):591-608. http://dx.doi.org/10.1177/1049732316665344. PMid:27670770.

15. Braun V, Clarke V. Reflecting on reflexive thematic analysis. Qual Res Sport Exerc Health. 2019;11(4):589-97. http://dx.doi. org/10.1080/2159676X.2019.1628806.
16. Marques ES, Moraes CL, Hasselmann MH, Deslandes SF, Reichenheim $\mathrm{ME}$. Violence against women, children, and adolescents during the COVID-19 pandemic: overview, contributing factors, and mitigating measures. Cad Saude Publica. 2020;36(4):e00074420. http://dx.doi. org/10.1590/0102-311x00074420. PMid:32374808.

17. Caron F, Plancq MC, Tourneux P, Gouron R, Klein C. Was child abuse underdetected during the COVID-19 lockdown? Arch Pediatr. 2020;27(7):399-400. http://dx.doi.org/10.1016/j.arcped.2020.07.010. PMid:32807622.

18. Seddighi H, Salmani I, Javadi MH, Seddighi S. Child abuse in natura disasters and conflicts: a systematic review. Trauma Violence Abuse. 2021;22(1):176-85. http://dx.doi.org/10.1177/1524838019835973. PMid:30866745.

19. Chandan JS, Taylor J, Bradbury-Jones C, Nirantharakumar K, Kane E, Bandyopadhyay S. COVID-19: a public health approach to manage domestic violence is needed. Lancet Public Health. 2020;5(6):e309. http://dx.doi.org/10.1016/S2468-2667(20)30112-2. PMid:32401709.

20. Carlos DM, Campeiz AB, Oliveira WA, Silva JL, Wernet M, Ferrian MGC. "I don't have it, I didn't have it": experiences of families involved in violence against children and adolescents. Rev Bras Enferm. 2020;73(Supl. 4):e20190195. http://dx.doi.org/10.1590/0034-71672019-0195. PMid:32756752.

21. Lei n. 14.022, de 7 de julho de 2020 (BR). Altera a Lei $n=13.979$, de 6 de fevereiro de 2020, e dispõe sobre medidas de enfrentamento à violência doméstica e familiar contra a mulher e de enfrentamento à violência contra crianças, adolescentes, pessoas idosas e pessoas com deficiência durante a emergência de saúde pública de importância internacional decorrente do coronavírus responsável pelo surto de 2019. Diário Oficial da União [periódico na internet], Brasília (DF), 8 jul 2020 [citado 4 out 2020]. Disponível em: http://www.planalto.gov. br/ccivil_03/_ato2019-2022/2020/lei/l14022.htm

22. Carlos DM, Pádua EMM, Silva LMP, Silva MAI, Marques WEU, Leitão MNCL et al. The care network of the families involved in violence against children and adolescents: the Primary Health Care perspective. J Clin Nurs. 2017;26(15-16):2452-67. http://dx.doi.org/10.1111/jocn.13692. PMid:28000373.

23. Teo SSS, Griffiths G. Child protection in the time of COVID-19. J Paediat Child Health. 2020;56(6):838-40. http://dx.doi.org/10.1111/jpc.14916. PMid:32468616.

24. Ghoshal R. Twin public health emergencies: Covid-19 and domestic violence. Indian J Med Ethics. 2020;5(3):195-9. http://dx.doi.org/10.20529/ IJME.2020.056. PMid:32546463.

25. Fegert JM, Vitiello B, Plener PL, Clemens V. Challenges and burden of the Coronavirus 2019 (COVID-19) pandemic for child and adolescent mental health: a narrative review to highlight clinical and research needs in the acute phase and the long return to normality. Child Adolesc Psychiatry Ment Health. 2020;14(1):20. http://dx.doi.org/10.1186/ s13034-020-00329-3. PMid:32419840. 